\title{
Promotion of almond oil from the Ferragnes variety, a predominant cultivar in young almond plantations in eastern Morocco
}

\author{
Reda Melhaoui ${ }^{1 *}$, Nadia Houmy ${ }^{1}$, Souhayla Kodad ${ }^{1}$, Kamal Belhaj ${ }^{1}$, Farid Mansouri ${ }^{1}$, Mohamed Addi ${ }^{1}$, \\ Malika Abid ${ }^{1}$, Aatika Mihamou ${ }^{1}$, Christophe $\mathrm{Hano}^{2}$, Marianne Sindic ${ }^{3}$, Hana Serghini C. ${ }^{1}$, Ahmed \\ Elamrani ${ }^{1}$ \\ ${ }^{1}$ Laboratory for Agricultural Productions Improvement, Biotechnology and Environment (LAPABE), Faculty of Sciences, \\ University Mohammed First, BP-717, 60000 Oujda, Morocco \\ ${ }^{2}$ Laboratoire de Biologie des Ligneux et des Grandes Cultures (LBLGC), INRAe USC1328, Université d'Orléans, 21 rue de \\ Loigny la Bataille, F-28000 Chartres, France. \\ ${ }^{3}$ Analysis Quality and Risk Unit, Laboratory of Food Quality and Safety (QSPA), Gembloux Agro-Bio Tech, University of \\ Liège, 5030 Gembloux, Belgium.3 High School Charlemagne, ISIa-Huy, Belgium
}

\begin{abstract}
Almond oil (AO) has both food and non-food uses, but the most profitable niche market is its non-food applications for cosmetic (Skincare, Body oil, Hair oil, Soap). In the last decade, two almond varieties Ferragnes and Ferraduel, with the dominance of Ferragnes, became to be crucial due to their suitability to the agro-ecological conditions of some regions of almond production in Morocco. This study focuses on characterization of $\mathrm{AO}$ of Ferragnes, which is the main cultivar among foreign almond varieties introduced in eastern Morocco. Chemical parameters' fatty acid (FA) composition, minor compounds mainly tocopherols and phenols were analyzed, and the oxidative stability (OSI) of AO related to their shelf life was determined. Results show low acidity $(0.38 \%)$ and low peroxide value $(1.92 \mathrm{meq} / \mathrm{kg})$. FA profile shows predominance of unsaturated FA principally oleic acid $(\mathrm{C} 18: 1 ; 68.9$ $\%)$ and linoleic acid (C18:2; 21.88\%). Tocopherol (Vitamin E) and phenol contents are, respectively, $456.43 \mathrm{mg} / \mathrm{kg}$ and $138 \mathrm{mg} / \mathrm{kg}$. In addition, due to its richness in natural antioxidants, this oil exhibits high oxidative stability (OSI $=24.09 \mathrm{~h}$ ); thus, these results prove the high quality of Ferragnes AO that can be recommended as edible oil, but notably for cosmetic applications which are more profitable.
\end{abstract}

\section{Introduction}

Almond trees (Prunus amygdalus Dulcis) are species native to Western Asia. Often Iran and surrounding countries are mentioned as origin areas, but currently, almond trees are widely cultivated elsewhere. Thus, due to its rusticity and its adaptation to drought climate, the almond tree has become the main tree nut in the Mediterranean area. It is a profitable crop that could be cultivated in very poor soils; however, the production will be as much higher as better the pedoclimatic conditions. Commonly the grown varieties are the result of a combination of human and natural selection [1].

Several studies have shown that the consumption of nuts is beneficial for the health and it has positive effects against many pathologies such as hypertension, obesity, and metabolic syndrome [2, $3]$.

Almonds contain vitamins, minerals, protein, and fiber, but the major constituent of almonds is oil, accounting for $40 \%$ to $67 \%$ of the dry weight of kernels [4].

Almond oil can be used in cooking and food preparation, but for better-added value, it is commonly used in the cosmetics industry in face and hair care, skin creams, and anti-aging products. Eating Almonds may offer several other health benefits including anti-inflammatory, antihepatotoxicity effects, immunity-boosting, and modulatory effects on inflammations [5].

In Eastern Morocco, the cultivation of almond trees has been developed in marginal agricultural areas due to the Moroccan-Belgian cooperation. In Fact, this concerns 6000 hectares of almond plantations and the development of the almond sector in this Region. This almond tree-growing program was a part of the Green Morocco Plan for sustainable development, aiming to increase incomes and to improve the quality of life of the population of these rural areas.

Two late-flowering cultivars, Ferragnes and Ferraduel, were used for the new almond plantings in eastern Morocco, but, this work is limited to the characterization and qualitative evaluation of almond oil (AO) from Ferragnès, which is the main cultivar among these two French's almond varieties recently introduced in eastern Morocco. Thus, fatty acid (FA) composition, minor compound contents, as well as the almond oil oxidative stability index (OSI) were determined.

*Corresponding author: reda melhaoui@ hotmail.fr 
The results of this study provide scientific information that can be useful for the valorization of $\mathrm{AO}$ in both food and non-food uses.

\section{Material and methods.}

\subsection{Almonds, growing conditions and sampling for oil extraction}

Almonds (Ferragnès variety) were provided by "GIE-Sidi Bouhria", which is an "economic interest group" consisting of farmers from this rural zone of Sidi Bouhria (3444'13.6” N, 002 20 '15.0”, W) and who help each other to develop the almond industry in eastern Morocco. Six $\mathrm{kg}$ of almond in shell (Ferragnes variety) were harvested from three almond orchards of this rural area, where almond culture is mainly rain-fed, but requiring additional irrigation during 2 to 3 months of recurrent dry periods. For instance, due to the low rainfall in 2018 (Fig. 1), almond trees received additional irrigation for 3 months (April to June).

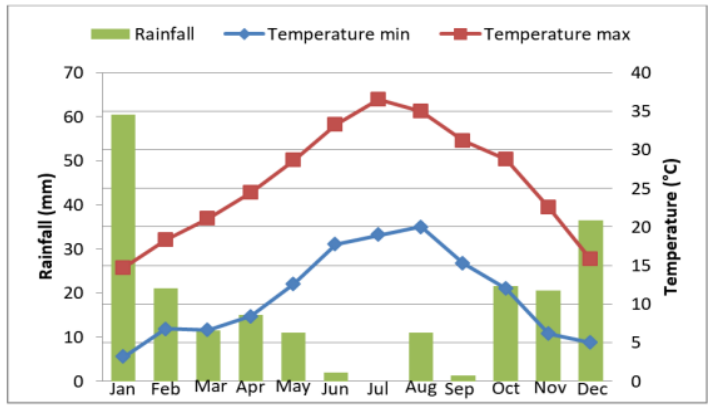

Fig. 1. Monthly accumulated rainfall, maximum and minimum temperatures registered in Sidi bouhria during the agricultural year 2018 (source: The National Meteorology Directorate)

The method for the recovery of almond oil is a mechanical screw pressing set to 70 RPM. The obtained crude almond oil is centrifuged at 3000 RPM /15 min for removing fine particles. The resulting clarified almond oil is stored in the dark at $4^{\circ} \mathrm{C}$ until using for further analyses.

\subsection{Analytical methods}

The evaluation of almond oil of Ferragnes was carried out on triplicate for each parameter

\subsubsection{Physicochemical parameter analysis and oxidative stability measurement}

Peroxide value $\left(\mathrm{meqO}_{2} / \mathrm{Kg}\right)$ and free acidity $(\%$ oleic acid), were determined according to the official European methods [6] for olive oil. Almond oil (AO) oxidative stability index (OSI) was determined according to the Rancimat Test (Metrohm apparatus model 743). The OSI of freshly extracted AO is expressed as the induction time in hours.

\subsubsection{Extraction and colorimetric determination of phenol contents}

Phenol contents were determined according to the method described by Ollivier et al. [7] and slightly modified by Mansouri et al. [8]. $5 \mathrm{~g}$ of almond oil was added to $5-\mathrm{mL}$ of a methanol/water solution (80/20. v/v), after 10 min of mixing the small vials of liquids in a quickly oscillating circular motion using a vortex, the mixture oil-methanol was centrifuged at $3800 \mathrm{rpm}$ for $15 \mathrm{~min}$. This operation was repeated twice and the methanolic phase was recuperated. The phenolic content was determined according to the Folin-Ciocalteu method, using caffeic acid as a standard by absorbance at $750 \mathrm{~nm}$.

\subsubsection{Total tocopherols analysis}

Tocopherols ( $\alpha, \beta, \gamma$ isomers) profile was performed according to the AOCS method Ce 8-89 AOCS, [6] by HPLC-FLD, equipped with a fluorescence detector and an automatic injector. The separation of tocopherols isomers was carried out on an Uptisphere $120 \mathrm{~A}^{\circ} \mathrm{NH}_{2}$ column $(150 \mathrm{~mm} * 3 \mathrm{~mm}, 3$ $\mu \mathrm{m}$, Interchim, Montluçon, France), maintained at $30{ }^{\circ} \mathrm{C}$. The injection volume was $10 \mu \mathrm{L}$. The mobile phase was hexane/2-propanol (99:1, v/v) eluted in isocratic conditions at a flow rate of $1 \mathrm{~mL}$.min-1. The tocopherols were identified and quantified by external standardization.

\subsubsection{Fatty acid analysis}

Fatty acids of almond oils were identified by standard composed of 37 methyl esters of fatty acids. Before analysis, fatty acids were converted into fatty acid methyl esters, after adding $8 \mathrm{~mL}$ of hexane, the mixture was performed by gaschromatograph analysis using an HP 6890 series gas chromatography system equipped with FID detector and a capillary column (Supelco Omega wax: $30 \mathrm{~m} \times 0.25 \mathrm{~mm} \times 0.25 \mu \mathrm{m}$. The injection volume was $1 \mu \mathrm{l}$ in split-less mode. This method of analysis was described by [8].

\section{Results and discussion}

\subsection{Almond oils' physicochemical indexes}

Low acidity and peroxide index values indicate freshness and good quality of oils and absence of enzymatic or chemical hydrolysis of acylglycerols [9]. In addition, the peroxide index is an indicator of the primary oxidation products (hydroperoxides). Tested oils that present high peroxide index values generally contain secondary oxidation products such as ketones, aldehydes, short hydrocarbon chains, and alcohols [10]. Results observed for Ferragnes almond oils (Table 1 ) show low acidity $(0.38 \%)$ and low peroxide value $(1.92 \mathrm{meq} / \mathrm{kg})$, which indicate good quality of analyzed almond oils. 
Table 1. Quality indexes of almond oils of the Ferragnes variety produced in eastern Morocco.

\begin{tabular}{|c|c|}
\hline $\begin{array}{c}\text { Physicochemical quality } \\
\text { parameters }\end{array}$ & $\begin{array}{c}\text { Ferragnes } \\
\text { Almond oil }\end{array}$ \\
\hline Free acidity (\% C18:1) & $0.38 \pm 0.04$ \\
\hline peroxide value meq $\mathbf{O}_{\mathbf{2}} \mathbf{k g}-\mathbf{1}$ & $1.92 \pm 0.60$ \\
\hline oxidative stability (h) & $24.09 \pm 0.50$ \\
\hline
\end{tabular}

\subsection{Total phenols and Tocopherol content of almond oils}

Phenolic compounds are natural secondary metabolites that present many biological effects, where the antioxidant capacity is the most important characteristic meanly for its beneficial impact on health [11].

The concentrations of total phenolic content in the analyzed almond oils present a value of $138 \mathrm{mg} / \mathrm{kg}$. Other studies by Rabadán et al. and Ozcan et al. [12, 13] have shown values of phenol content ranging from $18.53 \mathrm{mg} / \mathrm{kg}$ to $237 \mathrm{mg} / \mathrm{kg}$.

Generally, this variation depends on several factors, such as variety, oil extraction method, and agricultural practices. Tocopherols are presented by four homologs ( $\alpha$-, $\beta$-, $\gamma$-and $\delta$-tocopherols), as determined by the position and the number of methyl groups on the chromanol ring [14]. Almond oils extracted from Ferragnes were analyzed for their quantitative and qualitative tocopherol contents. Profile analysis showed the presence of three tocopherol homologs ( $\alpha$-, $\beta$ and, $\gamma$-tocopherol) with the $\alpha$-tocopherol as a dominant compound. Tocopherol compositions in almond oil are summarized in Table 2.

Table 2. Total phenols and tocopherol isomers composition of almond oil (Ferragnes variety) produced in eastern Morocco.

\begin{tabular}{|c|c|}
\hline $\begin{array}{c}\text { Phenols and Tocopherol } \\
\text { isomers }\end{array}$ & $\begin{array}{c}\text { Ferragnes } \\
\text { Almond oil }\end{array}$ \\
\hline Total phenols(mg/Kg) & $138 \pm 6.63$ \\
\hline $\boldsymbol{\alpha}$-tocopherol(mg/Kg) & $448.83 \pm 2.93$ \\
\hline $\boldsymbol{\beta}$-tocopherol(mg/Kg) & $2.43 \pm 0.01$ \\
\hline $\boldsymbol{\gamma}$-tocopherol(mg/Kg) & $6.26 \pm 0.1$ \\
\hline total tocopherol(mg/Kg) & $457.52 \pm 2.93$ \\
\hline
\end{tabular}

Almond oil shows a richness of tocopherols up to $456.43 \mathrm{mg} / \mathrm{kg}$. These three homologs of tocopherols were found in similar studies with also a dominance of $\alpha$-tocopherol [15-17]. In Morocco, limited studies have been conducted to determine the tocopherol profile of the Ferragnes variety cultivated in the country. Kodad et al. [18] have found approximate results for total tocopherols along with $461.9 \mathrm{mg} / \mathrm{Kg}$. The richness of tocopherols in almond oil contributes to the antioxidant properties of oils; they also have protective roles in biological systems as well as other neuroprotective properties [19]. Our results are similar to those recorded in Spain 475 $\mathrm{mg} / \mathrm{kg}$ [20] and higher compared to the ones obtained in Turkey $(186.6 \mathrm{mg} / \mathrm{kg})$ [21]

\subsection{Fatty acid profile}

Table 3 provides the fatty acid composition of mechanically extracted almond oil of Ferragnes variety. Oleic acid (C18:1), linoleic acid (C18:2), and palmitic acid (C16:0) are the three predominant fatty acids with values of $68.94 \%, 21.88 \%$, and $7.02 \%$, respectively. Also, the analysis shows the presence of four minor fatty acids, C18:0 (Stearic acid) of $1.63 \%, \mathrm{C} 17: 1$ (margaroleic), C17:0 (Margaric acid) of $0.03 \%$, and C16:1 (Palmitoleic acid) of $0.43 \%$. The fatty acid profiles of almond oils show a low percentage of saturated fatty acids (SFA) of $8.68 \%$ which is nutritionally undesirable except for C18:0, that it is considered as less hypercholesterolemic because it is extensively converted to oleic acid [22]. On the other side, the proportion of Monounsaturated fatty acids (MUFA) and polyunsaturated fatty acids (PUFA) content in almond oil is $69.47 \%$ and $21.88 \%$, respectively. Several studies refer to the benefits of MUFA intake on the risk factors of cardiovascular disease and the blood lipid profiles. Furthermore, the consumption of PUFA has demonstrated physiological benefits on heart rate, triglycerides, blood pressure, endothelial function, and cardiac diastolic function $[23,24]$. The ratio $\mathrm{O} / \mathrm{L}$ presents a value of 3.15. This parameter can be employed to characterize almond oils and kernel cultivars [25], and also the stability of oil.

Table 3. Fatty acid composition of almond oil of the Ferragnes variety (SFA: Saturated Fatty Acids; MUFA: Monounsaturated Fatty Acids; PUFA: polyunsaturated

\begin{tabular}{|c|c|}
\multicolumn{2}{|c|}{ Fatty Acids) } \\
\hline Fatty acids & Ferragnes \\
\hline Palmitic acid (C16:0) & $7,02 \%$ \\
\hline Palmitoleic acid (C16:1) & $0,43 \%$ \\
\hline Margaric acid (C17:0) & $0,03 \%$ \\
\hline Margaroleic (C17:1) & $0,10 \%$ \\
\hline Stearic acid (C18:0) & $1,63 \%$ \\
\hline Oleic acid (C18:1) & $68,94 \%$ \\
\hline Linoleic acid (C18:2n6) & $21,88 \%$ \\
\hline SFA & $8,68 \%$ \\
\hline MUFA & $69,47 \%$ \\
\hline PUFA & $21,88 \%$ \\
\hline O/L ratio & 03,15 \\
\hline
\end{tabular}

\subsection{Oxidative stability}

An important quality parameter of vegetable oil is its oxidative stability index (OSI), which allows the prediction of its shelf life and refers to the sensitivity of vegetable oils to lipid oxidation, which can lead to undesirable flavours and smells. Rancimat tests for oxidative stability of vegetable oils, by measurements of the induction period (OSI in hours) were performed at temperature $100^{\circ} \mathrm{C}$ for many samples of Ferragnes almond oil. The result for analyzed oils showed a high oxidative stability 
value (average OSI $=24.09 \mathrm{~h}$ ). Several similar studies on the oxidative stability of almond oil are presented in the literature where similar results are shown. For instance, in recent studies the mean OSI values observed for cold pressed nuts oils vary from 16.3 to 24.2 h [12,26], while Kochhar and Henry, [27] reported much lower values ( OSI $=10.2 \mathrm{~h}$ ). The observed different values for induction periods seem to be mainly related to the variation of the oil major and minor components notably fatty acid profile phenols and tocopherols. In addition, oils' oxidative stability could be affected by the oil extraction process and the storage conditions namely light, temperature, and oxygen availability [28].

\section{Conclusion}

The Fatty acid profile of freshly pressed almond oil of Ferragnes variety shows a very low percentage of SFA $(8.68 \%)$ and a high percentage of unsaturated fatty acids (MUFA+PUFA $=91.35 \%$ ); thus, this almond oil (AO) presents a fatty acid composition that is highly favorable for human nutrition as edible oil.

The analyzed samples of this almond oil have low acidity and low peroxide values but shown high values of the oxidation stability index (OSI) determined by the rancimat test, which indicates good stability of this AO for long shelf life. The richness of this almond oil of the Ferragnes variety in natural antioxidants (tocopherols and phenols) makes it a very interesting vegetable oil for several food supplement applications in relation to its beneficial health properties. However, the use in the cosmetics industry is still the most important and the more profitable.

\section{References}

1. A. El Hamzaoui, A. Oukabli, J. Charafi, M. Moumni, Sci Hortic, 154, 37-44 (2013)

2. A. Bechthold, H. Boeing, C. Schwedhelm, G. Hoffmann, S. Knüppel, K Iqbal, et al., Crit Rev Food Sci Nutr. Taylor \& Francis, 59, 1071-90 (2017)

3. D. Aune, N. Keum, E. Giovannucci, L.T. Fadnes, P. Boffetta, D.C. Greenwood, et al., BMC Med [Internet]. (2016)

4. J.M. Roncero, M. Álvarez-Ortí, A. PardoGiménez, R. Gómez, A. Rabadán, J.E. Pardo, Riv Ital Delle Sostanze Grasse. Innovhub SSIAREA SSOG via Giuseppe Colombo 79, milano, 20133, italy. 93, 237-43 (2016)

5. T-K. Lin, L. Zhong, J.L. Santiago, Int J Mol Sci, 19, 70 (2018)

6. A.O.C.S, Offic. Method (Ce 8-89). (1989)

7. D. Ollivier, E. Boubault, C. Pinatel, S. Souillol, M. Guérère, J. Artaud, Ann Expert Forum Chem Toxicol, 169-96 (2004)
8. F. Mansouri, A Benmoumen, G. Richard, M-L Fauconnier, M. Sindic, H. Serghini-Caid, et al., Riv Ital Sostanze Grasse. 93, 21-30 (2016)

9. M. Álvarez-Ortí, C. Quintanilla, E. Sena, A. Alvarruiz, J.E. Pardo, Grasas Aceites, 63, 2606 (2012)

10. P. Baltazar, N. Hernández-Sánchez, B. Diezma, L. Lleó, Agronomy. Multidisciplinary Digital Publishing Institute. 10, 41 (2020)

11. B.D. Oliveira, A.C. Rodrigues, B.M.I. Cardoso, A.L.C.C. Ramos, M.C. Bertoldi, J.G. Taylor, et al., Ind Crops Prod. 84, 59-66 (2016)

12. A. Rabadán, M. ÁlvarezOrtí, R. Gómez, C. Miguel de, J.E. Pardo, J Sci Food Agric, 98, 2402-10 (2018)

13. M.M. Ozcan, B. Matthaeus, F. Aljuhaimi, I.A.M. Ahmed, K. Ghafoor, E.E. Babiker, et al., J. Food Sci. Technol-Mysore, 57, 4182-92 (2020)

14. X. Liu, S. Wang, E. Masui, S. Tamogami, J. Chen, H. Zhang, Anal Lett. Taylor \& Francis, 1-10 (2020)

15. Y. Zhu, K.L. Wilkinson, M. Wirthensohn, Sci Hortic, 225, 150-5 (2017)

16. Y. Zhu, C. Taylor, K. Sommer, K. Wilkinson, M. Wirthensohn, Food Chem. 173, 821-6 (2015)

17. M. Kornsteiner, K-H. Wagner, I. Elmadfa, Food Chem. 98, 381-7 (2006)

18. O. Kodad, G. Estopanan, T. Juan, A. Mamouni, I. Socias R. Company, J Agric Food Chem, 6137-41 (2011)

19. C.K. Sen, S. Khanna, S. Roy, Mol Aspects Med. 28, 692-728 (2007)

20. R.M. Ojeda-Amador, G. Fregapane, M.D. Salvador, 121, 1900114 (2019)

21. M.M. Özcan, F. Al Juhaimi, K. Ghafoor, E.E. Babiker, M.M. Özcan, J. Food Sci. Technol. Springer, 57, 955-61 (2020)

22. E. Emken. J Oleo Sci. 62, 245-55 (2013).

23. J. Aranceta, C. Pérez-Rodrigo, $\mathrm{Br} \mathrm{J}$ Nutr. Cambridge University Press, 107, S8-22 (2012)

24. S.K. Gebauer, T.L. Psota, W.S. Harris, P.M. Kris-Etherton, Am J Clin Nutr, 83, 1526S1535S (2006)

25. A.C. Csakvari, A. Lupitu, S. Bungau, M.A. Gitea, D. Gitea, D.M. Tit, et al., Farmacia. Soc Stiinte Farmaceutice Romania Bucuresti, STR Traian Vuia 6, Sect 1. 67, 882-7 (2019)

26. A. Rabadán, J.E. Pardo, R. Gómez, M. Álvarez-Ortí, LWT, 93, 354-61 (2018)

27. S.P. Kochhar, C.J.K. Henry, Int. J. Food Sci. Nutr, Taylor \& Francis, 60, 289-96 (2009)

28. A. Rabadán, M. Álvarez-Ortí, J.E. Pardo, A. Alvarruiz, Food Chem, 259, 31-5 (2018) 